\title{
Treinamento e Desenvolvimento: Foco na Área de Vendas
}

\author{
Training and Development: Focus on Sales Area
}

\author{
Natani A. dos Santos ${ }^{\text {a }}$ Antônio Carlos Estender*ab \\ aUniversidade Guarulhos. SP, Brasil.

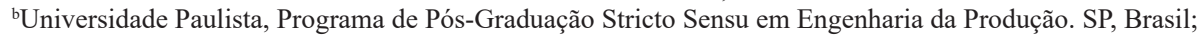 \\ *E-mail: estender@uol.com.br
}

\begin{abstract}
Resumo
O presente trabalho busca gerar conhecimentos para a aplicação prática, visa também solucionar problemas específicos, no caso, avaliar a eficiência dos treinamentos oferecidos para a área de vendas. Objetivo: analisar a metodologia de aplicação dos módulos de treinamento para área de vendas no ramo de Construção Civil. Método: o trabalho foi realizado por meio de estudo de caso, entrevistas, de natureza qualitativa e exploratória, sendo a coleta de dados realizada através de um questionário destinado aos colaboradores. Resultados: o levantamento de dados realizado na empresa XYZ (nome fictício) possibilitou identificar a importância da customização dos treinamentos, ou seja, tornar colaboradores da área de vendas verdadeiros especialistas em seu mercado de atuação e treiná-los de acordo com a complexibilidade do produto ou serviço oferecido para o cliente. Conclusão: a força de vendas é o oxigênio da empresa; o treinamento e desenvolvimento é uma das diversas ferramentas para desenvolver habilidades e competências capazes de fazer diferença no resultado de uma organização.
\end{abstract}

Palavras-chave: Treinamento. Desenvolvimento. Vendas. Capacitação.

\begin{abstract}
This study seeks to generate knowledge for practical application, also aims to solve specific problems, in this case, to assess the training effectiveness provided to the sales area. Objective: To analyze the application of training modules methodology for the sales area, in the Construction industry. Method: The study was conducted through case studies, interviews, qualitative and exploratory nature, with data collection conducted through a questionnaire for employees. Results: The data survey in XYZ Company (fictitious name) enabled us to identify the importance of training customization, that is to make sales are employees experts in their market, train them according to the complexity of the product or service offered to the customer. Conclusion: the sales force is the oxygen of the company; training and development is one of several tools to develop skills and abilities capable of making a difference in the outcome of an organization.
\end{abstract}

Keywords: Training. Development. Sales. Capacity.

\section{Introdução}

Kanaane e Ortigoso (2001) vêm analisando o Treinamento e Desenvolvimento com foco na área de Vendas, conforme apontado na revisão de literatura, em seus diferentes níveis de entendimento e aplicação ao contexto organizacional. Pode-se encontrar na literatura definições para Treinamento e Desenvolvimento com foco na área de vendas, o que demanda a construção de um modelo teórico/gerencial, que explicite como esses diferentes conceitos se articulam e podem contribuir para o entendimento de propostas de desenvolvimento organizacional.

Xavier (2006) afirma, ainda, que mobilizar os recursos para o treinamento implica em reunir material para desenvolvimento, definir as tarefas de treinamento para as pessoas e contratar serviços, sejam esses internos ou externos. $\mathrm{O}$ investimento em qualificiação tende a trazer diversos benefícios para a organização e seus colaboradores. Nesse sentido, o treinamento passa a ter um papel importante para a organização em busca de vantagens competitivas.

$\mathrm{Na}$ literatura acadêmica sobre Treinamento e
Desenvolvimento, o foco na área de vendas está relacionado com o setor de Construção Civil e existem poucos estudos sobre o tema (BURGESS et al., 2005). Os trabalhos identificados na literatura do Brasil foram Chiavenato (2009) e Cobra (1994), que mais vezes apareceram na literatura.

Como avaliar a eficiência dos treinamentos oferecidos para a área de vendas? Por que adaptar o linguajar utilizado nos treinamentos aos segmentos de atuação dos vendedores? Quais os benefícios que essas ações trazem para a organização?

Os objetivos deste trabalho envolvem analisar a metodologia de aplicação dos módulos de treinamento para área de vendas; refletir sobre como o treinamento pode influenciar nos resultados da empresa; identificar possíveis soluções para melhorar o desempenho dos vendedores e representantes de vendas; discutir a possibilidade de criar módulos de treinamento adaptado ao segmento do vendedor ou representante, com um linguajar específico; identificar quais são as opiniões dos funcionários/colaboradores; elaborar ações baseadas nas percepções das situações vivenciadas pelos colaboradores para produção de ações, que possibilitem atingir estes objetivos. 
O presente estudo visou contribuir para a elucidação de questões relacionadas aos dois temas: treinamento e desenvolvimento e vendas nas empresas. O treinamento é uma das ferramentas para avaliar o desempenho dos colaboradores, na área de vendas não é diferente. Além de melhorar os indicadores de vendas de produtos e serviços, um bom treinamento traz oportunidades para a organização e seus clientes, além do aumento da produtividade, melhoria de mão de obra e, consequentemente, a elevação do lucro, garantindo a estabilidade econômica das organizações. Almeja-se preencher a lacuna empírica/gerencial identificada na relação entre treinamento e desenvolvimento em vendas. $\mathrm{O}$ presente estudo constitui uma contribuição para compreender os fatores competitivos do ramo de Construção Civil.

Observou-se que o treinamento é uma ferramenta de gestão importante para o bom desempenho da organização. Ao capacitar/ treinar seus colaboradores, a empresa renova o CHA (Conhecimentos, Habilidades e Atitudes) do seu capital intelectual e, consequentemente, diminui os erros cometidos no dia a dia. A adaptação do treinamento ao segmento de atuação, perfil do cliente e público-alvo também são consideradas vantagens competitivas, já que esta ação tornaria a empesa e seus vendedores especialistas de mercado.

\section{Desenvolvimento}

\subsection{Treinamento e vendas}

Marras (2009) afirma que treinamento é o processo de aquisição de conhecimento e tem como consequência o desenvolvimento do indivíduo, mas também de suas competências e habilidades em determinadas funções, visto que a aquisição de conhecimento desenvolve habilidades e competências, que influenciam diretamente no desempenho do treinado, que passa a desenvolver melhor suas atividades e, consequentemente, trazendo um bom resultado para a organização.

Na visão de Chiavenato(2009), o treinamento é um processo educacional de curto prazo, aplicado de maneira sistemática e organizada. O treinamento é uma fonte de lucratividade ao permitir que as pessoas contribuam, efetivamente, para os resultados do negócio. O treinamento nada mais é do que o ensino teórico das habilidades necessárias para uma determinada função, o desempenho das atividades práticas do treinado é de total responsabilidade deste e do gestor, que deve acompanhar o desenvolvimento de seu subordinado.

Para se executar um planejamento eficiente da força de vendas são necessárias ações como localizar e focar ações em seu mercado alvo, avaliar e atender as necessidades de seus clientes, criar produtos e serviços para isso; descobrir quem são seus concorrentes, quais são os pontos fortes e fracos, o que estão fazendo e onde pretendem chegar, criar uma estratégia de sucesso competitivo; antecipar-se às mudanças do mercado, acompanhando as tendências e planejando ações futuras; identificar oportunidades para desenvolver novos produtos e serviços inéditos, baseados nos anseios do mercado; definir quais ações tomar para alcançar o melhor resultado, no menor prazo e com um mínimo de investimentos; criar uma seleção mais eficiente de canais e ações de propaganda e publicidade, suspendendo gastos com o que não traz resultados, por isso, com base no trabalho da área de vendas se pode definir o perfil do vendedor e os mecanismos a serem utilizados para seu desenvolvimento profissional e melhorar seu desempenho em determinadas atividades, embora muitas empresas não invistam na capacitação da equpe de vendas atavés do treinamento.

$\mathrm{Na}$ visão de Kanaane e Ortigoso (2001), a avaliação de desempenho está associada às atitudes do cotidiano. Essa análise ocorre em parâmetros subjetivos e personalizados, logo, é a análise de forma particular da aplicação do conhecimento, a criatividade e o potencial do indivíduo, ainda que não seja realizada diariamente, tal avaliação é imprescindível para acompanhar o desempenho do colaborador e da organização.

De acordo com Moreira e Munck (2010), o treinamento vem sendo utilizado com objetivo de desenvolver pessoas, para aprender novas habilidades e lembrar as que já existem, todavia, o aprendizado dos processos depende unicamente da dedicação do treinado, logo, a metodologia utilizada nos treinamentos é um fator determinante para o fracasso ou sucesso deste, sendo que é necessário ter pleno conhecimento do público-alvo, neste caso, vendedores e representantes de vendas e buscar especializá-los no mercado em que atua.

Para Cobra (1994), a atividade de vendas é classificada como ferramenta promocional entre propaganda, promoção e vendas, mas também merchandising e relações públicas, logo, elaborar módulos de treinamento de acordo com o segmento de atuação na área é extremamente importante, pois forma o colaborador especialista em setor de atuação.

De acordo com Castro Neves (2006), o processo de vendas é uma sequência de passos ou etapas através dos quais os vendedores realizam a venda. Sendo a pré-venda, venda e pós-venda importantes etapas para o sucesso do processo, portanto, pode-se afirmar que o treinamento é uma ferramenta que influencia no sucesso ou fracasso da empresa, visto que a capacitação do vendedor pode melhorar os resultados da organização, fazendo com que a tarefa seja realizada com eficiência e excelência.

Educar é construir, é libertar o homem do determinismo, passando a reconhecer o papel da História e a questão da identidade cultural, tanto em sua dimensão individual, como na prática pedagógica proposta, logo, pode-se entender que a educação, bem como o conhecimento sobre um determinado tema se torna um diferencial para o indivíduo que a obtém, contudo, especificamente na área de vendas, o vendedor já possui o conhecimento geral sobre o produto ou serviço que a organização oferece, sendo necessário buscar capacitação em seu segmento de atuação, tornar-se especialista, investir na especialização de vendedores é uma grande estratégia na 
busca de resultados.

Na opinião de Moreira (2000), o objetivo da força de vendas é possuir linguagem, comportamento e postura adequada ao padrão de mercado do cliente atendido, portanto, a especialização do vendedor e o conhecimento sobre o segmento de atuação do seu cliente acabam fazendo parte do seu perfil de venda, pois o linguajar utilizado na aquisição do conhecimento pode dificultar o entendimento do treinado, quando não é adaptada ao nível de conhecimento do indivíduo.

Treinamento remete a um processo educacional de curto e médio prazo, aplicado de maneira organizada, por meio do qual as pessoas adquirem conhecimentos, posições e habilidades em função de objetivos previamente definidos dentro de uma instituição organizacional, trata-se de elemento chave da eficácia profissional com o propósito de aumentar a produtividade sem prejudicar ou influenciar em seus comportamentos, pois o treinamento não é apenas um método de ensino, mas sim uma ferramenta capaz de desenvolver habilidades e competências que antes não existiam no perfil desse colaborador, que vai desempenhar bem suas fnuções, trazendo resultado para sua área de atuação e, por conseguinte para a empresa, através do feedback constante dos gestores da área.

Na opinião de Futrell (2003), venda se refere ao modo com que é feita a comunicação para convencer um cliente potencial a adquirir alguma coisa, seja essa um bem ou um serviço que atenda as suas necessidades, contudo, a capacitação dos vendedores resulta no desenvolvimento de suas habilidades, inclusive a de barganha para negociação e venda, que impactam diretamente no resultado da organização, entretanto, é necessário que o Gerente de Vendas ou Gestor responsável pratique o feedback com o vendedor para identificar quais são os gaps do cotidiano desse claborador e trabalhar em cima das soluções.

Para Galbreath e Rogers (1999), muitas empresas se preocupam apenas com a venda e não com a satisfação do cliente e suas necessidades, logo, o feedback com o cliente e o vendedor (pós-venda) também é um fator relevante para o alavancamento de vendas, entretanto, uma venda bem realizada leva a oganização ao sucesso e fideliza os consumidores, logo, é imprescindível ter uma equipe de venda treinada para atender as espectativas da empresa, do gestor e do cliente.

Segundo Mory (2004), o feedback é o processo de comunicação realizado de gestor para subordinado e vice e versa e tem por objetivo informar o treinado ou aprendiz sobre seu desempenho em determinadas atividades, logo, o feedback possibilita que o indivíduo faça comparação da sua perfomance atual com a esperada ou o padrão da organização, portanto, a prática dessa ação influencia diretamente na motivação e no desempenho do colaborador.

Segundo o dicionário Michaelis (2010), Feedback está definido como uma ação de controle retroativo, o mesmo que realimentação em cibernética, e retroação em psicologia, como por exemplo, testes práticos ou teóricos, no caso de vendedores, a simulação da forma correta de oferecer o produto ou serviço para o cliente, assim avaliar um treinamento é identificar a eficácia dos módulos.

\subsection{Estudo de Caso}

O Estudo de Caso como método que apresenta melhor aderência ao objetivo e às questões norteadoras do trabalho. Tull e Hawkins (1976, p. 323) afirmam que "um estudo de caso se refere a uma análise intensiva de uma situação particular". De acordo com Yin (2005), a preferência pelo uso do estudo de caso deve ser no estudo de eventos contemporâneos, em situações em que os comportamentos relevantes não podem ser manipulados, mas em que seja possível fazer observações diretas e entrevistas.

Para Quivy e Campenhoudt (1998), no método de observação é importante ressaltar que este implica um alto grau de subjetividade, uma vez que as pessoas se manifestam de acordo com sua vivência, histórico de valores e aspectos culturais. Utiliza-se este tipo de pesquisa empírica quando se quer conseguir informações e conhecimento referentes a um determinado problema do qual se busca comprová-lo, ou ainda, com a intenção de descobrir novos fenômenos, percepções ou relações entre esses. O termo pesquisa empírica, concisamente, se define como: (1) o modo de fazer pesquisa por meio de um objeto localizado dentro de um recorte do espaço social. A pesquisa empírica está centrada na escolha de aspectos das relações entre sujeitos. (2) A pesquisa empírica lida com processos de interação e face a face, isto é, o pesquisador não pode elaborar a pesquisa em "laboratório" ou em uma biblioteca, isolada e apenas com livros a sua volta. Nesta modalidade da elaboração do conhecimento, o pesquisador precisa "ir ao campo".

O conhecimento empírico é conceituado por Fachin (2003), como a resposta para ocorrências baseadas na vivência, experiência de erros e de acertos, que não possuem fundamentação metodológica. Ramos, Ramos e Busnello (2005) acrescentam o conceito anterior à concepção do autor, em que o conhecimento empírico é estabelecido pela experiência do outro da interação humana e social, na qual são explicitados conhecimentos implícitos individuais. Entre as metodologias ao alcance, os pesquisadores as agrupam em dois níveis: 1. Metodologias Qualitativas e Observaçãoparticipante. 2. Entrevistas não estruturadas e/ou depoimentos. A pesquisa empírica implica em refletir acerca da relação que se estabelece entre o sujeito e o objeto da pesquisa.

Para o desenvolvimento da pesquisa, em termos metodológicos, adota-se a abordagem qualitativa, segundo Collis e Hussey (2005). Em relação aos procedimentos foram realizadas entrevistas, as pesquisas desse tipo se caracterizam pela interrogação direta das pessoas, cujo comportamento se deseja conhecer. Basicamente, procede-se à solicitação de informações via questionários a um grupo significativo de pessoas, acerca do problema estudado para, em seguida, 
mediante análise, obter as conclusões correspondentes aos dados coletados. A população entrevistada foi de 25 colaboradores de diferentes hierarquias, as amostras foram analisadas de forma empírica, na empresa XYZ (nome fictício), na cidade de Guarulhos.

\subsection{Análise da unidade}

A empresa foi fundada na França por ordem do Rei Luis XIV, em 1665, criada por Colbert com o objetivo de produzir os espelhos para o Palácio de Versalhes. Ao longo do tempo, a empresa desenvolveu outras atividades implantandose em todas as regiões do mundo. Hoje, a empesa XYZ (nome fictício) é um grupo multinacional, fabricante de materiais tecnológicos diversificados é líder mundial nas suas atividades. Transforma materiais conhecidos de longa data, tais como: o vidro, o ferro fundido, o plástico, as cerâmicas e os abrasivos. Nesses materiais, agrega todo o seu conhecimento e experiência adquiridos ao longo desses três séculos, para atender a um mercado moderno, com necessidades cada vez mais complexas e exigentes.

A empresa XYZ possui uma equipe comercial de aproximadamente 200 colaboradores, sendo esses: Gerentes de Vendas, Vendedores e Representantes de Vendas. É oferecida para essa equipe treinamentos técnicos, nos diversos segmentos nos quais a organização atua, e percebeu-se que, apesar de serem treinados para aprimorar suas habilidades de negociação, de persuasão e de conhecimento do negócio, a área de vendas perde diversas oportunidades em clientes por falta de conhecimento sobre os produtos básicos e técnicos fabricados pela empresa, a falta de conhecimento gera insegurança ao vendedor no momento de ofertar o produto para o consumidor.

O linguajar utilizado nos treinamentos é muito técnico e, muitas vezes, não é adequado para a capacitação dos treinados, nesse caso, colaboradores que atuam na área de vendas já que a empresa atua em diversos segmentos diferentes, sendo esses: Industrial, Automotivo e Varejo. O perfil do vendedor/ representante é classificado de acordo com seu segmento de atuação, e a necessidade do conhecimento a ser adquiro também deve ser definida dessa maneira, sendo classificado entre nível básico e técnico, pois a complexibilidade dos produtos desses segmentos é variável de acordo com o padrão do consumidor final.

Atualmente, todos são treinados para tudo, gerando desmotivação e acomodação por parte do vendedor treinado, já que ele tem consciência de que não irá utilizar as informações daquele treinamento no seu dia a dia nas atividades que desenvolve. A organização acaba treinando por treinar e desperdiça recursos, que poderiam ser investidos em treinamentos com foco na especialização da equipe de vendas.

\subsection{Análise de dados}

A análise das entrevistas foi feita de maneira empírica e interpretativa, por meio da utilização da análise de conteúdo.
Esse tipo de pesquisa busca apontar os "comos", e os "porquês" embasados nos discursos oriundos da análise das entrevistas levando-se em consideração as significações, procurando identificar as percepções dos funcionários/colaboradores sobre o tema. Um dos propósitos da utilização das entrevistas, como método de coleta de dados, na pesquisa qualitativa, é explorar percepções, experiências, crenças e/ou motivações dos funcionários/colaboradores sobre questões específicas no campo organizacional.

A análise foi feita em duas etapas: a) análise e compreensão das pesquisas bibliográficas e/ou documentais feitas sobre o tema; b) análise e compreensão das entrevistas realizadas. Sabe-se que, desse modo, a metodologia qualitativa na pesquisa empírica, ao estabelecer relações face a face entre o "sujeito que pesquisa" com o "sujeito que é pesquisado", permite vínculos de reflexão entre as partes envolvidas, porque estão todos em presença, isto é, frente a frente e em diálogo.

Em conformidade com Flores (1994), o roteiro de entrevistas foi elaborado em função dos objetivos e da questão de pesquisa, e foi guiado pelos principais tópicos levantados. Sendo uma pesquisa qualitativa, não existe uma rígida delimitação em relação ao número adequado de sujeitos da entrevista, pois é um dado que pode sofrer alterações no decorrer do estudo, além disso, pode haver necessidade de complementação de informações, ou também, em caso de esgotamento, à medida que as respostas se tornam redundantes.

As entrevistas para esse trabalho foram realizadas, individualmente, no local de trabalho, com funcionários/ colaboradores de diferentes níveis hierárquicos. Essas foram realizadas entre os dias 15/02 e 21/05 do ano de 2016. Para se atingir os propósitos deste estudo se buscou formular um roteiro de entrevistas embasado na teoria descrita. Os dados foram levantados por meio de revisão de literatura, que foi desenvolvida a partir de material já elaborado, constituído principalmente de livro e de artigos científicos, para dar o devido suporte teórico-acadêmico ao estudo Diehl e Tatim (2004). Efetuou-se a pesquisa de campo e entrevistas em profundidade, com questões não estruturadas com 25 entrevistados de nível técnico e gerencial, funcionários da empresa XYZ (nome fictício), atuantes na cidade de Guarulhos, ligados à área de Construção Civil.

Segundo Rynes e Gephart (2004), um valor importante da pesquisa qualitativa é a descrição e compreensão das reais interações humanas, percepções, sentidos, e processos que constituem os cenários da vida organizacional. De acordo com Merriam (1998), estudos qualitativos interpretativistas podem ser encontrados em disciplinas aplicadas em contextos da prática. Os dados são coletados por meio de entrevistas, de observações e/ou de análise de documentos. O que é perguntado, o que é observado e quais documentos são relevantes dependerá da revisão da literatura.

A coleta de dados ocorreu por meio de entrevista semiestruturada. Neste tipo de trabalho, o pesquisador 
deve seguir um conjunto de questões previamente definidas, mas ele o faz em um contexto muito semelhante ao de uma conversa informal, tendo abertura para incluir novas questões, se necessário, e análise de documentos, por meio das questões elaboradas se buscou compreender a metodologia de aplicação dos módulos de treinamento para área de vendas.

Para que estes objetivos fossem atingidos, planejou-se uma pesquisa baseada na aplicação de um questionário qualitativo a partir de entrevistas, sendo este composto por perguntas básicas sobre o respondente e sua empresa. As perguntas foram elaboradas, levando-se em consideração aspectos que poderiam, de certa forma, influenciar o funcionamento da empresa XYZ (nome fictício), tendo o estudo como principal alicerce autores como os citados na revisão de literatura. Apesar da amostra não ser representativa, essa é conveniente em função da disposição dos respondentes em participar da pesquisa e responder ao questionário de forma bastante detalhada. Foram entrevistadas 25 pessoas.

\subsection{Discussão}

Os resultados descritos a seguir foram baseados nas informações colhidas nas entrevistas e nos sites da organização. Estas contribuíram para complementar o estudo. Os resultados visaram responder: como avaliar a eficiência dos treinamentos oferecidos para a área de vendas? As discussões apresentadas buscam traduzir a interpretação do pesquisador, construída a partir da análise das respostas obtidas pelas entrevistas realizadas, bem como os dados obtidos a partir da observação in loco. As informações foram trabalhadas de forma a apresentar as percepções dos colaboradores com a finalidade de elaborar ações, que venham a contribuir para o treinamento e o desenvolvimento com foco na área de vendas.

A despeito das limitações da pesquisa, a primeira dessas está relacionada à amostra analisada e seu caráter não probabilístico, que impedem que os resultados gerados por essa pesquisa sejam generalizados para todo o segmento ou para todas as empresas e, a segunda, por se tratar de um caso único, não possibilita a comparação com outras empresas, a fim de identificar as semelhanças e as diferenças existentes.

Quadro 1 - Percepções acerca do treinamento e desenvolvimento: foco na área de vendas.

\begin{tabular}{|c|c|}
\hline Gerentes (5) & 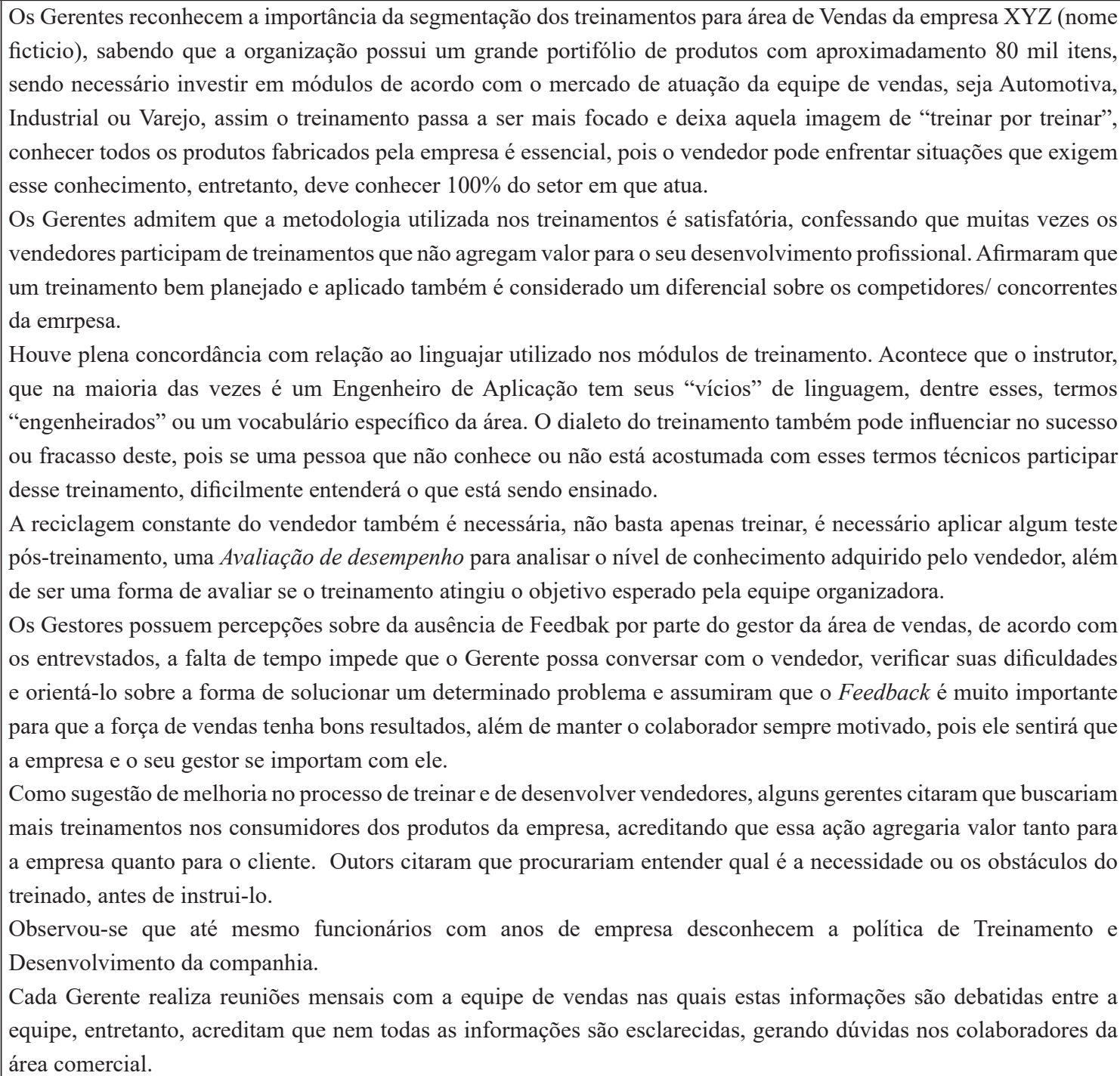 \\
\hline
\end{tabular}




\begin{tabular}{|c|c|}
\hline & 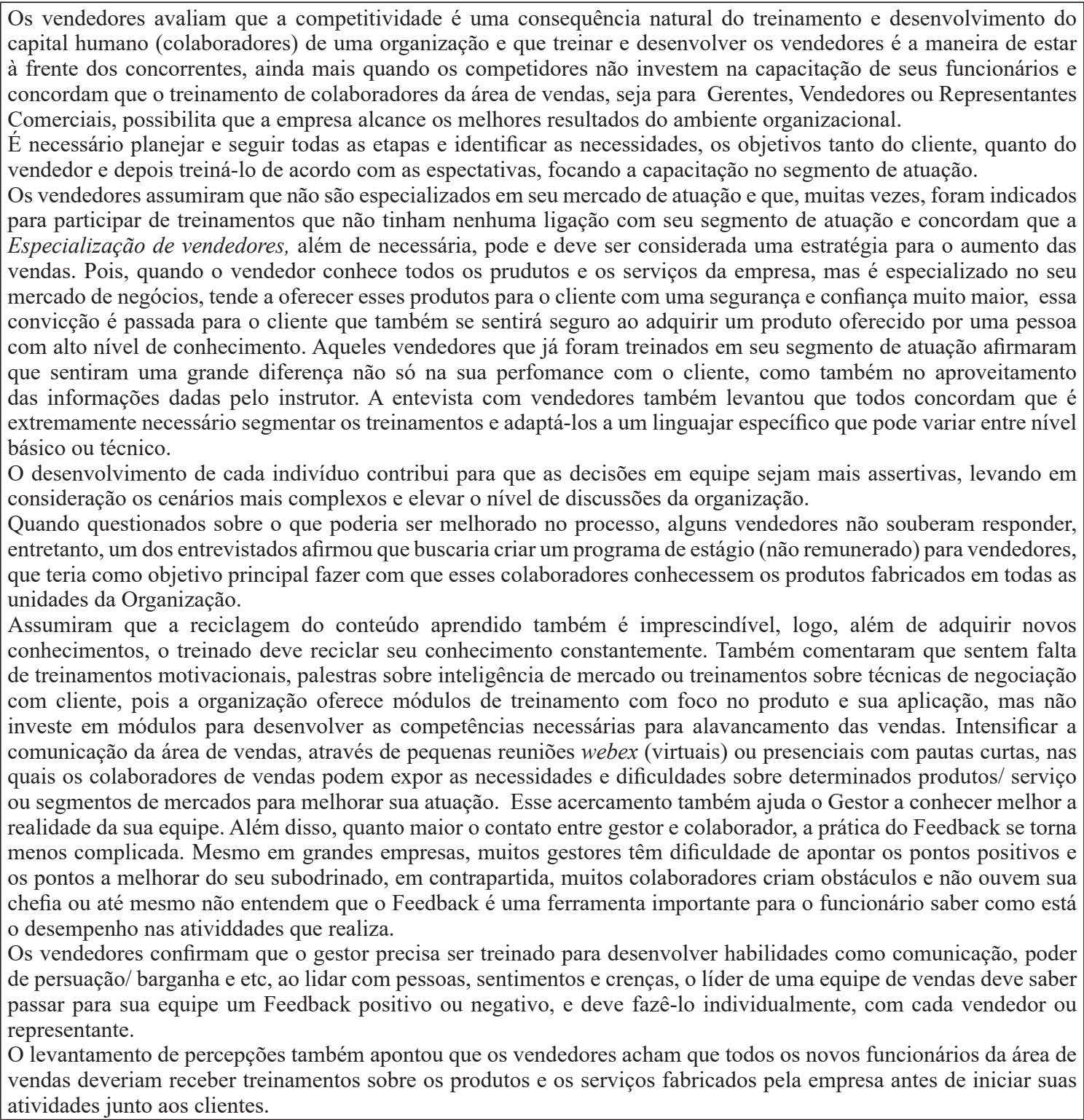 \\
\hline & $\begin{array}{l}\text { Os Engenheiros de Aplicação acreditam que o treinamento e desenvolvimento da área de vendas podem influenciar } \\
\text { diretamente no sucesso ou fracasso da organização. } \\
\text { Afirmam que a especialização dos vendedores e representantes traria um bom retorno para a empresa, pois desta } \\
\text { maneira o foco será maior, e a equipe estará muito mais preparada para as dificuldades do mercado. Confirmam que } \\
\text { não se pode instruir um vendedor Industrial da mesma maneira que se treina um Vendedor do varejo. Desta forma, } \\
\text { se a pessoa treinada foi bem orientada, estará comprometida com os objetivos da empresa, sabendo como é e de qual } \\
\text { maneira deve buscar a excelência do seu trabalho. } \\
\text { Quando questionados sobre o que poderia ser melhorado no processo, os Engenheiros de Aplicação afirmaram que } \\
\text { buscariam avaliar sempre se o treinamento em questão é importante para o bom desenvolvimento do treinado. O } \\
\text { objetivo do treinamento precisa estar claro tanto para os participantes, nesse caso colaboradores da área de vendas, } \\
\text { quanto para os instrutores, engenheiros de aplicação e todos precisam estar engajados em um mesmo objetivo, fazer com } \\
\text { que todos sigam um mesmo caminho para atingir as metas estabelecidas. Além disso, disponibilizariam informações } \\
\text { como as apresentações dos respectivos treinamentos, datas de realização, duração, local, material didático, vídeos, } \\
\text { exercícios passo a passo com resolução detalhada para que o vendedor possa ter acesso e consultar esse material no } \\
\text { futuro, se necessário. } \\
\text { Os engenheiros assumem que o linguajar utilizado nos módulos de treinamento da XYZ (nome ficticio) é muito técnico } \\
\text { e que, muitas vezes, há uma má classificação de participantes, ou seja, vendedores que não atuam no mercado do } \\
\text { treinamento dado. Concordam que a especialização dos vendedores é importante e que a organização precisa investir } \\
\text { em módulos de treinamento mais segmentados, com menos foco no produto e mais no processo, no mercado e no } \\
\text { cliente. Em compensação, não basta só investir em capacitação, é necessário avaliar o vendedor através da Avaliação } \\
\text { de desempenho com o objetivo de melhorar sua performance junto ao cliente. }\end{array}$ \\
\hline
\end{tabular}


Os grupos de entrevistados estão diretamente relacionados com o tema, pois os Engenheiros de Aplicação ministram todos os treinamentos destinados para a equipe comercial, que é composta pelos Gerentes de Vendas e Vendedores/ Representantes. Ambos devem estar focados em um único objetivo para atingir os resultados, trabalhar com um propósito em comum, para obter um retorno positivo para a empresa, seja esse financeiro ou marketing share.

As entrevistas foram realizadas com três grupos de colaboradores, dentre esses: Gerentes de vendas, Vendedores e Engenheiros de Aplicação. A semelhança entre os entrevistados é a concordância sobre a importância do treinamento nos resultados da organização, também para a competitividade e a fidelização do cliente. A empresa procura lançar no mercado produtos tecnológicos, que oferecem soluções para os consumidores, entretanto, é necessário investir em quem oferece esses produtos no mercado, ou seja, os vendedores. Alguns entrevistados citaram que, em alguns casos, o dialeto utilizado nos treinamentos é muito "engenheirado", ou seja, técnico demais e dificulta o entendimento do assunto que está sendo ensinado.

Para compreender melhor a problemática apontada neste estudo e as possíveis soluções para este, buscou-se analisar as contribuições dadas pelos grupos nas entrevistas. A avaliação de desempenho, Especialização de Vendedores e Feedback foram as recomendações dadas para resolver o problema identificado na organização, com base no cotidiano desses colaboradores/funcionários.

Ainda, de acordo as entrevistas, foram identificadas diferenças em relação à disponibilização das informações para a área de vendas, para alguns a empresa dissemina todos os dados necessários para alavancar as vendas, por outro lado, outros discordaram dessa afirmação, informando que existem gaps (falhas) no processo de comunicação da organização, dados como oportunidades de mercado, de prospecção de clientes não são repassados para área de vendas. A ausência dessas informações dificulta o trabalho do vendedor, que se prepara para atender ao cliente de acordo com o padrão estabelecido pelo mesmo. Os dados apontam a necessidade de investimento em métodos e módulos de treinamento para área comercial.

Todos os entrevistados estão envolvidos no processo de Treinamento e Desenvolvimento da equipe comercial. Observou-se que cada grupo possui fraquezas e limitações, que podem prejudicar e que devem ser levadas em consideração. Os Gerentes de Vendas entendem que todos precisam de capacitação, mas não aceita que o treinamento pode ter perdido sua eficiência por falta de interessa dos vendedores. Quanto aos Vendedores, perceberam-se limitações com relação à disposição de tempo para participar ativamente dos treinamentos voltados para o seu respectivo segmento de atuação. Já os Engenheiros de Aplicação entendem que existe uma falta de interesse por parte dos Gerentes e Vendedores, que sugerem que as propostas de melhoria deste processo devem partir da própria equipe.

Conforme o levantamento de dados (entrevistas), a tendência é segmentar os treinamentos de acordo com o ramo de atuação do vendedor (automotivo, industrial ou varejo), com a elaboração de módulos mais focados nesses mercados. Essa ação irá provocar melhorias no desempenho do colaborador, além de desenvolver habilidades e competências capazes de fazer toda diferença para o vendedor e para o cliente, trazendo segurança e conforto no momento da oferta. Além de torná-los especialistas.

As entrevistas apontaram a necessidade de criar um método de avaliação de desempenho (pós-treinamento) que, de acordo com Kanaane e Ortigoso (2001), a avaliação de desempenho está associada às atitudes do cotidiano. Essa análise ocorre em parâmetros subjetivos e personalizados, logo, é análise de forma particular da aplicação do conhecimento, a criatividade e o potencial do indivíduo, ainda que não seja realizada diariamente, tal avaliação é imprescindível para acompanhar o desempenho do vendedor e da organização.

Sabe-se que a organização precisa se preocupar com seu capital humano, seus planos de carreira, objetivos pessoais e profissionais. Uma organização que investe no crescimento pessoal e profissional de seu funcionário, ao mesmo tempo está investindo na sua motivação para desempenhar da melhor forma as suas atividades. O treinamento e o desenvolvimento de profissionais traz um ganho imensurável tanto para a organização quanto para o indivíduo, entretanto, não basta apenas treinar, é necessário fazer uma avaliação do treinado após a sua participação no treinamento, medir os conhecimentos adquiridos e aqueles que devem ser aperfeiçoados.

Identificou-se que os vendedores não são especializados em seu segmento de atuação, ou seja, são treinados para tudo, é necessário criar módulos de treinamento segmentados para a especialização dos vendedores que, segundo MOREIRA (2000), o objetivo da força de vendas é possuir linguagem, comportamento e postura adequada ao padrão de mercado do cliente atendido, portanto, a especialização do vendedor e o conhecimento sobre o segmento de atuação do seu cliente acabam fazendo parte do seu perfil de venda, pois a linguagem utilizada na aquisição do conhecimento pode dificultar o entendimento do treinado, quando não é adaptada ao nível de conhecimento do indivíduo. Especializar a equipe de vendas é determinar se a equipe será dividida por algum critério (CASTRO; NEVES, 2008).

O treinamento e o desenvolvimento de vendedores é considerado um diferencial sobre a concorrência, pessoas mais capacidatas trazem melhores resultados, aumentam a quantidade de clientes e fidelizam aqueles que já consomem os produtos e serviços oferecidos. No entanto, não basta apenas treinar, ou capacitar sem um objetivo específico. Especializar o vendedor no seu segmento de atuação pode melhorar seu desempenho nas atividades, aumentar a segurança e a credibilidade do cliente, tanto no vendedor que atende, quanto na organização, que fará com que o cliente se sinta seguro em 
consumir aquele bem.

De acordo com a percepção dos entrevistados, identificouse a necessidade da prática do Feedback (pós-venda) com os vendedores/Representantes de Vendas, e segundo Mory (2004), o feedback é o processo de comunicação realizado de gestor para subordinado e vice e versa e tem por objetivo informar o treinado ou aprendiz sobre seu desempenho em determinadas atividades, assim, o feedback possibilita que o indivíduo compare sua perfomance atual com a esperada ou o padrão da organização, portanto, a prática dessa ação influencia diretamente na motivação e no desempenho do colaborador.

Segundo Moreira (2009), o feedback é a capacidade de dar e receber opiniões, críticas e sugestões sobre algo pessoal ou profissional. Torna-se uma das características que um líder deve desenvolver ao longo de sua carreira. Portanto, pode-se afirmar que feedback, além de ser uma ferramenta eficaz de gestão, também é muito importante na vida de um profissional em ascensão, no caso de vendedores, a simulação da forma correta de oferecer o produto ou serviço para o cliente, logo, avaliar um treinamento é maneira de identificar a eficácia dos módulos.

É evidente que a organização deve prezar por seus bens e clientes, mas não existem dúvidas de que o capital mais importante de uma empresa é o humano (colaboradores). É esse capital o gerador de ideias criativas e inovadoras, que facilita os processos, cria a tecnologia, além de ser a principal fonte de comunicação de uma organização. Uma das práticas dessa comunicação é o Feedback, que nada mais é do que uma avaliação realizada de gestor para subordinado e vice e versa. O Feedback pode influenciar diretamente na motivação do colaborador e, consequentemente, no desempenho das suas atividades, pois o Gerente pode expor ao colaborador os pontos fortes e aqueles que precisam se aperfeiçoados, no caso da área de vendas, o Feedback é essencial, podendo ser realizado em conjunto (Gestor e equipe) e individualmente (Gestor e colaborador). Nessa avaliação, o vendedor tem liberade para apresentar os principais obstáculos que enfrenta no seu dia a dia e buscar as possiveis formas de solucionar um problema, principalmente, após ter participado de um treinamento, no qual receberá informações que irão favorecer sua atuação no mercado.

Criar um programa de estágio não remunerado para a equipe de vendas, para que possam acompanhar os engenheiros de aplicação em visitas às fábricas de abrasivos, possibilitando o aumento do conhecimento sobre os produtos e serviços oferecidos pela empresa. O estágio será realizado para a área de vendas da organização estudada e a equipe de Recursos Humanos indicará o Engenheiro de Aplicação responsável pela supervisão e acompanhamento dos estagiários, essa ação será realizada nas fábricas de Abrasivos da empresa XYZ (nome fictício), localizadas em: Guarulhos, Caieiras, Igarassu, Jundiaí e Vinhedo e o tempo para implantação é de um ano, devido todo planejamento necessário para realização dessa ação e disponibilização do budget para gastos com transportes, coffees e materiais que serão utilizados nas visitas.

Os efeitos da inexistência de um programa de treinamento são colaboradores da área de vendas com anos de empresa que não conhecem os produtos que são fabricados pela empresa, muitas vezes, porque não são treinados em seus respectivos segmentos de atuação, gerando desperdício de recursos para a organização. Por não receber o devido treinamento, os vendedores ficam desconfortáveis e inseguros no momento de ofertar o produto ou serviço para o cliente.

Por outro lado, a causa dessa ação intensificaria o processo de ensino e aprendizagem com foco na área de vendas, com o objetivo de aumentar o nível de conhecimento, de acordo com o mercado de atuação desse colaborador e torná-lo um especialista para que se sinta à vontade e seguro no momento de ofertar o produto para o cliente e negociar a venda.

Diminuir o hábito cultural de "treinar todos para tudo". O conhecimento geral sobre os produtos e serviços oferecidos pela empresa é essencial, entretanto, capacitar o vendedor/ representante de acordo com seu segmento de atuação não é só uma estratégia para o aumento das vendas, mas também da produtividade desse colaborador, que vai se sentir seguro em oferecer um produto do qual ele conhece e tem todas as informações necessárias. Essa ação será realizada no departamento de Engenharia de Aplicação da XYZ (nome fictício), unidade Guarulhos. O prazo é de um ano devido ao planejamento financeiro da área de Recursos Humanos e da necessidade de criar novos módulos de treinamento específicos e segmentados que ainda não existem.

Elevar a divulgação dos treinamentos disponíveis para capacitação da equipe e aumento da força de vendas, em diversos casos, os vendedores não conhecem todos os módulos de treinamento oferecidos pela empresa e o gestor imediato também não passa essa informação para sua equipe, muitas vezes essa notícia também não chega até aos Gerentes de Vendas para que repassem a sua respectiva equipe. Essa ação será realizada pelos departamentos de Comunicação Interna, Engenharia de Aplicação e Recursos Humanos que vão analisar todos os canais de comunicação da organização com o objetivo de identificar as possíveis falhas no processo de disseminação e o prazo para implantação é imediato, não há necessidade de investimentos financeiros, pois a empresa já utiliza diversos canais para divulgar outros eventos realizados na organização e suas unidades.

\section{Conclusão}

Os objetivos deste trabalho foram analisar a metodologia de aplicação dos módulos de treinamento para área de vendas, refletir sobre como o treinamento pode influenciar nos resultados da empresa, para tal foi realizado um estudo de caso, com abordagem qualitativa por meio de entrevistas, na empresa XYZ (nome fictício) no setor de Construção Civil. A revisão de literatura sugere que existe uma relação entre treinamento e vendas. 
A princípio, tinha-se receio de que o questionamento sobre os temas desta pesquisa não fossem bem compreendidos pelos colaboradores durante a entrevista, porém foi surpreendente o entendimento deles quanto aos assuntos tratados, acreditandose de que isso se deve pela própria rede de informações que faz parte de seu cotidiano.

Os principais resultados mostraram que os objtivos foram alcançados, sendo o treinamento uma ferramenta que influencia diretamente na força de vendas de uma organização. A percepção dos colaboradores da XYZ (nome fictício) apresentou concordância plena que a especialização de vendedores, ou seja, a elaboração de módulos de treinamento segmentado é uma forma de diminuir ou até mesmo eliminar os gaps, as principais dificuldades que os vendedres enfrentam no momento de oferecer o produto para o cliente. Identificase que o linguajar utilizado nos treinamentos, assim como os módulos, também devem ser segmentados, ua vez que a empresa possui um grande porifólio de produtos, entre esses: produtos complexos e básicos, a equipe de vendas precisa receber treinamentos diferentes, com linguajar adptado para o seu respectivo segmento, seja esse técnico ou básico. Após o levantamento de dados acerca dessa temática se pode afirmar a necessidade de avaliar o desempenho do colaborador, após participação no treinamento e a prática de feedbak entre gestores e subordinados, nesse caso, Gerentes de Vendas e Vendedores.

Como sugestão de estudos futuros, é necessário ampliar a amostra para outras revisões de literatura, ampliar o período de tempo para possibilitar uma visão mais abrangente do emprego dos métodos de pesquisa, podendo apresentar contribuições significativas como, por exemplo, permitir novas contribuições metodológicas na área e ampliar a análise dos resultados e, por fim, a realização de futuras pesquisas ligando o tema Treinamento e Desenvolvimento: foco na área de vendas com as escolhas metodológicas, que se mostrariam relevantes no sentido de verificar tendências e oportunidades de pesquisa, para que os profissionais e gestores da área tenham mais clareza sobre o tema.

\section{Referências}

BURGESS, P.W. et al. The gateway hypothesis of rostral prefrontal cortex (area 10) function. In:. DUNCAN, J.; PHILLIPS, L.; MCLEOD, P. (Ed.) Measuring the mind: Speed, control. Oxford: Oxford University, 2005.

CASTRO, L.T.; NEVES, M.F. Administração de vendas: planejamento, estratégia e gestão. São Paulo: Atlas, 2008.

CASTRO, L.T.; NEVES, M.F. O processo de vendas. São Paulo: Atlas, 2006.

COBRA, M. Administração de vendas. São Paulo: Atlas, 1994.
COLLIS, J; HUSSEY, R. Pesquisa em administração: um guia prático para alunos de graduação e pós-graduação: um guia prático para alunos de graduação e pós-graduação dois. Porto Alegre: Bookman, 2005.

CHIAVENATO, I. Gestão de pessoas. São Paulo: Campus, 2009.

DIEHL, A.; TATIM, A. Pesquisa em ciências sociais aplicadas: métodos e técnicas. São Paulo: Pearson Prentice Hall, 2004.

FACHIN, O. Fundamentos de metodologia. São Paulo: Saraiva, 2003.

FUTRELL, C.M. Vendas: fundamentos e novas práticas de gestão. São Paulo: Saraiva, 2003.

FLORES, J.F. Análisis de dados cualitativos: aplicaciones a la investigación educativa. Barcelona: PPU, 1994.

FLEURY, M.T.L.; FLEURY, A. Construindo o conceito de competência. RAC, p.183-196, 2001.

GALBREATH, J.; ROGERS, T. Customer relationship leadership: a leadership and motivational model for the twenty-first century business. TQM Mag., v.11, n.3, p.161-171, 1999.

KANAANE, R; ORTIGOSO, S. A. Manual de treinamento e desenvolvimento do potencial humano. São Paulo: Atlas, 2001.

MARRAS, J.P. Administração de recursos humanos: do operacional ao estratégico. São Paulo. Saraiva, 2009.

MERRIAM, S.B. Qualitative research and case study applications in education. San Francisco: Jossey Bass, 1998.

MICHALIS, Dicionário. Moderno Dicionário da Lingua Portuguesa. São Paulo. Disponível em < http:// michaelis.uol.com.br/moderno/portugues/index. php?lingua $=$ portuguesportugues\&palavra $=$ feedback $>$ Acesso em: 10 set. 2018.

MOREIRA, J.C.T. Administração de vendas. São Paulo: Saraiva, 2000.

MOREIRA, C.E.R.; MUNCK, L. Estilos de aprendizagem versus treinamento vivencial ao ar livre. Santa Maria: UFSM. 2010

MOREIRA, B.L. Dicas de feedback: a ferramenta essencial da liderança. Rio de Janeiro: Oualitmark, 2009

MORY, E.H. Feedback research review. In: JONASSEM, D. Handbook of research on educational communications and technology. Mahwah: Lawrence Erlbaum, 2004. p.745-783.

QUIVY, R.; CAMPENHOUDT, L. Manual de investigação em Ciências Sociais. Lisboa: Gradiva, 1998.

RAMOS, P.; RAMOS, M.M.; BUSNELLO, S.J. Manual prático de metodologia da pesquisa: artigo, resenha, projeto, TCC, monografia, dissertação e tese. Blumenau: Acadêmica, 2005.

RYNES, S., GEPHART, R.P. From the editors: qualitative research and the Academy of Management Journal. Acad. Manag. J., v.47, n.4, p.454-461, 2004.

TULL, D.S.; HAWKINS, D.I. Marketing research, meaning, measurement and Method. London: Macmillan Publishing, 1976.

XAVIER, R. Gestão de pessoas na prática: os desafios e as soluções. São Paulo: Gente, 2006.

YIN, R.K. Estudo de caso: planejamento e métodos. Porto Alegre: Bookman, 2005. 